\title{
Differences in strength and landing biomechanics between female jumpers and swimmers
}

\author{
Mianfang Ruan ${ }^{\mathrm{a}, 1}$, Qiang Zhang ${ }^{\mathrm{b}, 1}$, Xin Zhang ${ }^{\mathrm{c}}$, Jing $\mathrm{Hu}^{\mathrm{c}}$ and $\mathrm{Xie} \mathrm{Wu}^{\mathrm{c}, *}$ \\ a School of Physical Education and Health, Wenzhou University, Wenzhou, Zhejiang, China \\ ${ }^{\mathrm{b}}$ Institute for Biomechanics, ETH Zürich, Zürich, Switzerland \\ ${ }^{\mathrm{c}}$ School of Kinesiology, Shanghai University of Sport, Shanghai, China
}

Received 15 April 2021

Accepted 25 June 2021

\begin{abstract}
.
BACKGROUND: It remains unclear if plyometric training as a single component could improve landing mechanics that are potentially associated with lower risk of ACL injury in the long term

OBJECTIVE: The purpose of this study was to investigate the influence of experience undertaking plyometrics on landing biomechanics in female athletes.

METHODS: Non-jumpers with little experience in plyometric training (12 female college swimmers) and jumpers with five years of experience in plyometric training (12 female college long jumpers and high jumpers) were recruited to participate in two testing sessions: an isokinetic muscle force test for the dominant leg at $120^{\circ} / \mathrm{s}$ and a $40-\mathrm{cm}$ drop landing test. An independent $\mathrm{t}$ test was applied to detect any significant effects between cohorts for selected muscle force, kinematic, kinetic, and electromyography variables.

RESULTS: While female jumpers exhibited greater quadriceps eccentric strength $(P=0.013)$ and hamstring concentric strength $(P=0.023)$ during isokinetic testing than female swimmers, no significant differences were observed in kinematics, kinetics, and muscle activities during both drop landing and drop jumping.

CONCLUSIONS: The results suggest that the female jumpers did not present any training-induced modification in landing mechanics regarding reducing injury risks compared with the swimmers. The current study revealed that plyometric training as a single component may not guarantee the development of low-risk landing mechanics for young female athletes.
\end{abstract}

Keywords: ACL injury, jumping, drop landing, 3D analysis, plyometric training

\section{Introduction}

Landing is an integral part of specialized movements in many sport activities [1]. The peak ground reaction force (GRF) generated when landing of a long jump can

\footnotetext{
${ }^{1}$ These authors have contributed equally to this work and share first authorship.

* Corresponding author: Xie Wu, School of Kinesiology, Shanghai University of Sport, Hengren Rd. 200, Shanghai 200438, China. Tel.: +86216 5507368; E-mail: wuxie_sus@163.com.
}

reach magnitudes as high as ten times body weight [2]. To effectively absorb this GRF as well as maintain balance, highly coordinated force production from the lower extremity musculature needs to be complemented with a well-balanced whole-body posture [3]. Landing from a jump is one of the most likely scenarios for non-contact anterior cruciate ligament (ACL) injury in athletes [4]. Female athletes have been reported to be 3-8 times more likely to have non-contact ACL injuries than their male counterparts $[5,6]$. Studies showed that the females land in a more extended knee position and 
tend to maintain this extended position subsequent to ground contact rather than absorb the impact with controlled knee flexion [7,8]. This knee extended position, combined with internal hip rotation, makes females vulnerable to ACL over-loading [9]. Therefore, such inadequate neuromuscular control leveraged by females during landing could limit their abilities to maintain normal landing mechanics and result in higher incidence of ACL injury. Although ACL injury in female athletes is a multifactorial problem, neuromuscular control is considered a major modifiable factor that can be addressed in a proper injury prevention program.

ACL-injury prevention training programs, usually composed of several different components including strength, balance, and plyometric training programs, have shown some success in lowering ACL injury risk in females $[10,11]$. Despite these developments, the annual incidence of ACL injuries has increased [5,12] and the associated gender difference remains constant or has even increased [13]. The disparity between successes in the laboratory and actual long-term effects on injury prevention might be partially attributed to difficulties with adherence to prevention programs [14-16]. A typical comprehensive prevention program often lasts from $30 \mathrm{~min}$ to $1 \mathrm{~h}$ and is meant to be performed three times per week [14]. Coaches may not be willing to allocate excessive time to the comprehensive prevention program if athletic performance has not improved [15]. A better understanding of how those components act individually in the long term could provide great insights into their individual functionality and may help to eliminate those redundant components incapable of improving neuromuscular control.

Plyometric training, incorporating a variety of jumping and landing exercises [17], is a training method for developing explosive power of the muscle through a rapid eccentric contraction prior to the concentric contraction [18]. Many sports coaches credit plyometric training for raising performance levels based on the evidence that it could enhance vertical jumping [19] and improve sprint speed [20] and the ability to change direction [21]. Plyometric training is also among the most important components of prevention training programs aimed at lowering the risk of non-contact ACL injuries [22,23]. However, although a limited number of studies have examined the short-term effects of plyometric training on landing biomechanics [24-26], it remains unclear if plyometric training as a single component could improve landing mechanics in the long term. Comparison of landing biomechanics between female jumpers who undertook chronic plyometric training and female non-jumpers (i.e. swimmers) who had almost no plyometric training experience may provide insights to this question and therefore facilitate the development of a more efficient and easily adhered prevention program

It is well documented that landing performance is dominated by eccentric contractions of lower extremity extensors during the landing phase and weaker knee strength in females has been related to a more extended knee position compared to that of males [9]. Since plyometric training is a great method of developing eccentric muscular strength [27], it is logical to hypothesize that female jumpers have greater peak knee eccentric extension strength and accordingly exhibit a less extended knee position compared to swimmers. Additionally, plyometric training may also improve dynamic balance, knee proprioception, and body mechanics [28]. Thus, we predict that jumpers may exhibit some additional low risk landing biomechanics.

Therefore, the purpose of our study was to compare eccentric knee strength as well as lower extremity kinematics, kinetics, and electromyography (EMG) during both drop landing and drop jumping between female jumpers and swimmers We hypothesized that the jumpers would have greater eccentric knee strength than the swimmers. We also hypothesized that the female jumpers would exhibit lower risk of ACL injury in landing kinematics and kinetics during both drop landing and drop jumping.

\section{Materials and methods}

\subsection{Participants}

Twenty-four female college athletes were recruited to participate in the study: 12 females were long jumpers or high jumpers who received regular training in jumping (plyometric) training that had started in their teenage years (age: $20.14 \pm 0.86 \mathrm{y}$; height: $171.1 \pm 5.7 \mathrm{~cm}$; weight: $58.86 \pm 6.37 \mathrm{~kg}$ ). The other 12 females were swimmers who received little training in jumping/plyometric training (age: $20.58 \pm 1.51 \mathrm{y}$; height: $167.9 \pm 3.9 \mathrm{~cm}$; weight: $62.42 \pm 5.74 \mathrm{~kg}$ ). All participants were injury-free at the time of testing. The study has been approved by the Ethics Committee of Scientific Study at Shanghai University of Sport (No. 102772021RT042) on Jan. 19th, 2021 and all participants have signed an informed consent form.

\subsection{Design and procedures}

Participants performed two test sessions on two consecutive days: an isokinetic lower extremity strength 

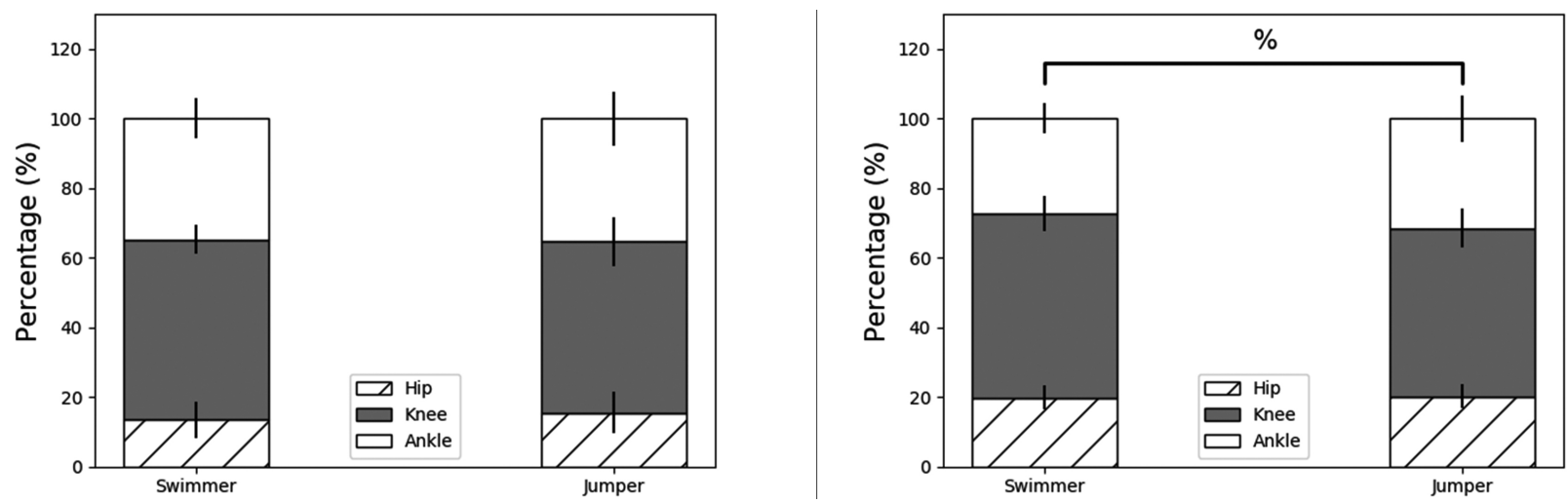

Fig. 1. Bar plots of joint contributions to total eccentric work during drop landings (left) and drop jumps (right). \% Significant difference between jumpers and swimmers in knee joint contribution.

test session and a drop landing test session. The order of the two sessions was randomly balanced across participants. The participants began with a standard warm-up of jogging on a treadmill for $5 \mathrm{~min}$ and stretching in both testing sessions. In the isokinetic lower extremity strength session, the hamstring concentric strength, the quadriceps concentric and eccentric strength of the dominant limb were measured using an isokinetic dynamometer (CON-TREX MJ; CMV AG Corp., Duebendorf, Switzerland). The dominant leg was determined as the self-reported take-off leg in the long jump. During the isokinetic knee strength test, the participant was instructed to sit on the dynamometer with the trunk perpendicular to the floor and hip flexion of $90^{\circ}$. The subject's knee joint was fixed at a starting flexion angle of $90^{\circ}\left(0^{\circ}\right.$ full extension). Following three submaximal trials, participants were instructed to perform three trials of maximum hamstring concentric contractions, and quadriceps eccentric and concentric contractions at an angular velocity of $120^{\circ}$ /s [29-31]. Quadriceps eccentric strength was measured when the quadriceps were eccentrically resisting a forced knee flexion. A two-minute rest was allowed between the concentric and eccentric measurements to prevent the occurrence of fatigue. The testing order of concentric and eccentric strength was randomly balanced across participants. The highest peak torque of the three maximal contractions for each test condition was chosen for data analysis.

In the drop landing test session, 3-dimensional (3D) kinematic and ground reaction forces (GRF) were collected using a 16-camera motion analysis system (200 Hz; Vicon Motion Analysis; Oxford, United Kingdom) and two force plates $(1,000 \mathrm{~Hz}$; Kistler Instruments, Winterthur, Switzerland). Simultaneously, electromyographic (EMG) activities of selected lower ex- tremity muscles were collected using a Delsys EMG system (2,000 Hz; Trigno wireless; Delsys, Boston, USA). The EMG system included wireless Ag electrodes with a parallel bar arrangement (contact area 1 $\times 10 \mathrm{~mm} ; 10 \mathrm{~mm}$ inter-electrode distance) and preamplifier close to the detection site (common-mode rejection ratio $>80 \mathrm{~dB}$, bandpass $=20-450 \mathrm{~Hz}$ ). The Vicon system, force plates and EMG system were systematically synchronized. Participant setup began with standardized skin preparation, including the shaving of hair and skin cleaning with alcohol. Then, wireless EMG electrodes were attached to the vastus medialis (VM), the long head of the biceps femoris (BF) and the medial head of the gastrocnemius (MG) of the participant's dominant leg. The rectangular $(25 \times 12 \times$ $7 \mathrm{~mm}$ ) electrodes were placed over the muscle belly aligned with the muscle fiber orientation and were secured with athletic tape to minimize motion artifacts. The distances between the electrodes were at least $3 \mathrm{~cm}$ to avoid any significant crosstalk. All participants wore the same type of running shoes during landing trials.

Retroreflective calibration markers $(14 \mathrm{~mm})$ were attached bilaterally on anatomical locations on the participant's body, including the iliac crest, anterior superior iliac spines, posterior superior iliac spines, greater trochanters, medial and lateral epicondyles of the knee, medial and lateral malleoli, first and fifth metatarsal heads, heels, and second toes. As the tracking marker sets, additional rigid plates with three markers were attached bilaterally to the thighs and lower leg (Fig. 1). Participants performed a static calibration trial with all markers presented. The calibration markers were then removed before the landing trials. After the calibration trial, participants completed a 5-min warm-up jogging on a treadmill, followed by three countermovement vertical jumps, with the highest jump used for EMG nor- 
malization. Afterwards, the participants were instructed to perform three drop landing trials by stepping off a 40$\mathrm{cm}$ platform and landing with two feet on two separate force plates, respectively. Then the participants were instructed to perform three drop jumping trials, in which the participants were required to jump as high as possible after landing from the $40-\mathrm{cm}$ platform $[32,33]$. To maintain consistent and reliable landing techniques during the testing session, the participants were instructed to keep their arms in front of the trunk with the elbows flexed [34]. The participants were also instructed to not control their knee depth. In addition, the participants were allowed to flex the trunk. No other verbal or visual instruction as to the landing style was given during the trials. The participants rested one minute after each trial so that the effect of muscle fatigue was eliminated.

\subsection{Data processing and analysis}

A 3D biomechanical analysis suite, Visual3D (CMotion, Inc., Germantown, MD, USA), was used to compute 3D kinematic and kinetic variables, as well as the EMG variables. The data were analyzed using a linked-segment model. The 3D angular kinematics were defined in a Cardan sequence (X-Y-Z), in which the order of rotation was flexion/extension (X-axis), abduction/adduction (Y-axis), and internal/external rotation (Z-axis). The right-hand rule was used to determine the polarity of the 3D angular kinematic and kinetic variables. The 3D marker coordinates and GRF signals were smoothed using a 4th-order Butterworth low-pass filter with cutoff frequencies of 10 and $100 \mathrm{~Hz}$, respectively. The jumping height during drop jumping was calculated as the vertical displacement of the marker on the participant's sacrum from the initial standing posture to the highest position in the air [32]. An inverse dynamics approach was used to calculate the joint kinetics. Joint powers were calculated as the product of the instantaneous joint moment and joint angular velocity. Joint mechanical work was calculated as the integration of joint power over the landing phase. Positive and negative work values indicate energy production and absorption through concentric and eccentric muscular contractions, respectively [35]. The individual joint work contribution was calculated as the joint work divided by total work of the lower extremity joints. The joint moments, joint powers, and joint mechanical work were normalized to body mass, and the GRF was normalized to body weight [36]. The landing phase for both the drop landing and drop jumping was defined as the duration from the initial foot contact with the force plate (initial contact; IC) to the time at maximum knee flexion [37]. The isokinetic muscle strength variables assessed in our study include peak eccentric quadriceps torque, peak concentric hamstring torques, and the ratios of peak concentric hamstrings torques and peak eccentric quadriceps torques $\left(\mathrm{H}_{\text {con }}: \mathrm{Q}_{\text {ecc }}\right)$ [38]. The kinematic variables include contact and peak angles of the ankle, knee, and hip, as well as joint range of motion (ROM). Peak vertical GRF, as well as peak joint moment, power, and work were included to evaluate changes in vertical impact forces and associated kinetics of three lower extremity joints.

Raw EMG signals were full-wave rectified and filtered using a moving root-mean-squared (RMS) filter with a window width of $50 \mathrm{~ms}$. The maximum RMS values of each muscle in the MVC testing were used to normalize the EMG of the respective muscle during landing. The normalized EMG signals were then integrated into two time intervals: from $100 \mathrm{~ms}$ prior to foot IC for the pre-activation phase and from foot IC to maximum knee flexion for the landing phase. The integrated EMGs were further divided by the respective time intervals to obtain average EMG (aEMG) values.

\subsection{Statistical analysis}

An independent-samples $t$ test was applied to detect significant differences between groups for isokinetic muscle strength, as well as kinematic, kinetic, and EMG variables during drop landing and drop jumping. The alpha level was set at 0.05 . Effects sizes (ES) were calculated using Cohen's $d$ [39] for each dependent variable to further evaluate statistical differences, and the interpretation of the results was based on the scale provided by Cohen [39]: 0.2 trivial effect; $0.2-0.5$ small effect; 0.5-0.8 medium effect; and over 0.8 large effect. Statistical analysis was performed using SPSS software (version 19.0; SPSS, Chicago, USA).

\section{Results}

\subsection{Muscle strength}

Significant differences between the jumpers and swimmers were observed for lower extremity muscle strength (Table 1). The peak eccentric torque of the quadriceps $(P=0.013)$ and concentric torque of the hamstrings $(P=0.023)$ were significantly greater in the jumpers than the swimmers, but differences were not observed for the peak quadriceps concentric torque and $\mathrm{H}_{c o n}: \mathrm{Q}_{e c c}$ ratio. 
Table 1

Means (SD), $t$ values, $P$ values and ES values associated with independent $t$ tests of isokinetic lower extremity strength of knee muscles at $120 \%$

\begin{tabular}{lccccc}
\hline & Swimmer & \multicolumn{1}{c}{ Jumper } & $t$ & \multicolumn{1}{c}{$P$} & \multicolumn{1}{c}{ ES } \\
\hline $\mathrm{Q}_{\text {con }}[\mathrm{Nm} / \mathrm{Kg}]$ & $1.57(0.42)$ & $1.73(0.47)$ & -0.871 & 0.394 & 0.36 \\
$\mathrm{Q}_{\text {ecc }}[\mathrm{Nm} / \mathrm{Kg}]$ & $1.99(0.51)$ & $2.61(0.55)$ & -2.724 & $0.013^{*}$ & 1.17 \\
$\mathrm{H}_{\text {con }}[\mathrm{Nm} / \mathrm{Kg}]$ & $0.96(0.11)$ & $1.11(0.17)$ & -2.464 & $0.023^{*}$ & 1.05 \\
$\mathrm{H}_{\text {con }} / \mathrm{Qecc}$ & $0.52(0.15)$ & $0.44(0.09)$ & 1.483 & 0.154 & 0.65 \\
\hline
\end{tabular}

Qcon: Peak quadriceps concentric torque; Qecc: Peak quadriceps eccentric

torque; Hcon: Peak hamstring concentric torque; ES: effect size.

Table 2

Means (SD), $t$ values, $P$ values and ES values associated with independent $t$ tests of ground impact variables and jumping height

\begin{tabular}{|c|c|c|c|c|c|c|c|c|c|c|}
\hline & \multicolumn{5}{|c|}{ Landing } & \multicolumn{5}{|c|}{ Drop jump } \\
\hline & Swimmer & Jumper & $t$ & $P$ & ES & Swimmer & Jumper & $t$ & $P$ & $\mathrm{ES}$ \\
\hline Peak VGRF [BW] & $5.15(1.12)$ & $5.89(1.51)$ & -1.359 & 0.188 & 0.56 & $3.75(0.37)$ & $4.46(0.80)$ & -2.794 & $0.011 *$ & 1.14 \\
\hline VGRF loading rate $[\mathrm{BW} / \mathrm{s}]$ & $32.89(7.88)$ & $39.24(12.21)$ & -1.514 & 0.144 & 0.62 & $23.12(2.61)$ & $28.31(8.17)$ & -2.093 & $0.048^{*}$ & 0.86 \\
\hline Jumping height $[\mathrm{m}]$ & & & & & & $0.24(0.04)$ & $0.3(0.05)$ & -3.439 & $0.002 *$ & 1.33 \\
\hline
\end{tabular}

ES: effect size.

Table 3

Means (SD), $t$ values, $P$ values and ES values associated with independent $t$ tests of lower extremity kinematic variables

\begin{tabular}{|c|c|c|c|c|c|c|c|c|c|c|}
\hline & \multicolumn{5}{|c|}{ Landing } & \multicolumn{5}{|c|}{ Drop jump } \\
\hline & Swimmer & Jumper & $t$ & $P$ & ES & Swimmer & Jumper & $t$ & $P$ & ES \\
\hline \multicolumn{11}{|l|}{ Hip } \\
\hline Flexion angle at $\mathrm{IC}\left[^{\circ}\right]$ & $38.85(4.58)$ & $36.84(6.16)$ & 0.906 & 0.375 & 0.37 & $44.46(5.64)$ & $45.33(6.28)$ & -0.357 & 0.725 & 0.15 \\
\hline Peak flexion angle $\left[{ }^{\circ}\right]$ & $60.33(10.05)$ & $59.73(15.03)$ & 0.115 & 0.909 & 0.05 & $82.12(6.61)$ & $73.8(8.21)$ & 2.733 & $0.012 *$ & 1.12 \\
\hline Joint ROM $\left[^{\circ}\right]$ & $21.48(7.9)$ & $22.89(11.95)$ & -0.34 & 0.737 & 0.14 & $37.66(4.20)$ & $28.47(9.50)$ & 3.064 & $0.006^{*}$ & 1.25 \\
\hline \multicolumn{11}{|l|}{ Knee } \\
\hline Flexion angle at $\mathrm{IC}\left[^{\circ}\right]$ & $22.17(4.47)$ & $21.33(4.94)$ & 0.435 & 0.668 & 0.18 & $28.60(5.34)$ & $29.81(4.75)$ & -0.589 & 0.562 & 0.24 \\
\hline Peak flexion angle $\left[{ }^{\circ}\right]$ & $82.88(11.37)$ & 77.15 (10.19) & 1.301 & 0.207 & 0.53 & $100.47(6.92)$ & $86.34(8.57)$ & 4.442 & $<0.001 *$ & 1.81 \\
\hline Joint ROM $\left[^{\circ}\right]$ & $60.71(9.94)$ & $55.82(10.6)$ & 1.167 & 0.256 & 0.48 & $71.87(6.25)$ & $56.53(9.38)$ & 4.715 & $<0.001 *$ & 1.92 \\
\hline \multicolumn{11}{|l|}{ Ankle } \\
\hline Plantarflexion angle at IC $\left[^{\circ}\right]$ & $32.96(5.24)$ & $30.01(6.09)$ & 1.271 & 0.217 & 0.52 & $30.27(5.16)$ & $24.89(6.47)$ & 2.248 & $0.035 *$ & 0.92 \\
\hline Peak dorsiflexion angle $\left[{ }^{\circ}\right]$ & $27.85(5.41)$ & $24.01(5.51)$ & 1.727 & 0.098 & 0.71 & $34.04(4.49)$ & $27.62(5.52)$ & 3.127 & $0.005^{*}$ & 1.28 \\
\hline Joint ROM $\left[{ }^{\circ}\right]$ & $60.81(5.17)$ & $54.01(4.91)$ & 3.304 & $0.003^{*}$ & 1.35 & $64.31(3.97)$ & $52.51(6.52)$ & 5.352 & $<0.001 *$ & 2.19 \\
\hline
\end{tabular}

ROM: range of motion; ES: effect size.

\subsection{Landing performance}

For the drop landing, no significant differences between the jumpers and the swimmers were observed for the peak GRF and the GRF loading rate (Table 2). For the drop jumping, the peak $\operatorname{GRF}(P=0.011)$ and GRF loading rate $(P=0.048)$ were significantly higher in the jumpers compared to the swimmers (Table 2). In addition, greater jumping height $(P=0.002)$ was observed in the jumpers than the swimmers for the drop jumping.

\subsection{Kinematics}

The mean values for each kinematic variable were compared for the drop landing between the jumpers and the swimmers (Table 3). The only significant difference observed was an overall smaller ankle ROM in the jumpers compared to the swimmers ( $P=0.003$ ). No significant differences between the jumpers and the swimmers were observed for the hip and knee kinematic variables.

For the drop jumping, significant differences were observed for the hip, knee, and ankle kinematic variables (Table 3). The peak flexion angles of the knee $(P<0.001)$ and hip $(P=0.012)$ joints were significantly smaller in the jumpers than the swimmers. In addition, the ankle plantarflexion angle at IC $(P=0.035)$ and peak dorsiflexion angle $(P=0.005)$ were significantly smaller in the jumpers than the swimmers. These differences resulted in significantly smaller joint ROM in the hip $(P=0.006)$, knee $(P<0.001)$, and ankle $(P<0.001)$ in the jumpers compared to the swimmers.

\subsection{Kinetics}

The mean values for each kinetic variable were com- 
Table 4

Means (SD), $t$ values, $P$ values and ES values associated with independent $t$ tests of lower extremity kinetic variables

\begin{tabular}{|c|c|c|c|c|c|c|c|c|c|c|}
\hline & \multicolumn{5}{|c|}{ Landing } & \multicolumn{5}{|c|}{ Drop jump } \\
\hline & Swimmer & Jumper & $t$ & $P$ & $\mathrm{ES}$ & Swimmer & Jumper & $t$ & $P$ & ES \\
\hline \multicolumn{11}{|l|}{ Hip } \\
\hline Peak extension moment $[\mathrm{Nm} / \mathrm{kg}]$ & $4.51(1.64)$ & $5.15(2.32)$ & -0.775 & 0.447 & 0.32 & $3.62(1.13)$ & $4.87(1.83)$ & -2.016 & 0.056 & 0.82 \\
\hline Peak eccentric power $[\mathrm{W} / \mathrm{kg}]$ & $22.07(10.17)$ & $25.19(12.62)$ & -0.667 & 0.512 & 0.27 & $21.24(8.07)$ & $27.17(10.64)$ & -1.538 & 0.138 & 0.63 \\
\hline Eccentric work $[\mathrm{J} / \mathrm{kg}]$ & $0.44(0.23)$ & $0.49(0.21)$ & -0.58 & 0.568 & 0.24 & $0.69(0.14)$ & $0.63(0.14)$ & 1.141 & 0.266 & 0.43 \\
\hline \multicolumn{11}{|l|}{ Knee } \\
\hline Peak extension moment $[\mathrm{Nm} / \mathrm{kg}]$ & $2.56(0.33)$ & $2.79(0.68)$ & -1.085 & 0.289 & 0.44 & $2.28(0.26)$ & $2.59(0.42)$ & -2.198 & $0.039 *$ & 0.89 \\
\hline Peak eccentric power [W/kg] & $26.19(3.32)$ & $29.32(9.11)$ & -1.12 & 0.275 & 0.46 & $21.63(3.44)$ & $24.04(6.69)$ & -1.11 & 0.279 & 0.97 \\
\hline Eccentric work $[\mathrm{J} / \mathrm{kg}]$ & $1.64(0.29)$ & $1.54(0.34)$ & 0.827 & 0.417 & 0.34 & $1.83(0.16)$ & $1.5(0.25)$ & 3.863 & $0.001 *$ & 1.57 \\
\hline ATSF (BW) & $0.92(0.09)$ & $1.02(0.13)$ & -2.048 & 0.053 & 0.89 & $0.82(0.08)$ & $1.00(0.12)$ & -4.245 & $<0.001 *$ & 1.77 \\
\hline \multicolumn{11}{|l|}{ Ankle } \\
\hline Peak plantarflexion moment $[\mathrm{Nm} / \mathrm{kg}]$ & $1.67(0.31)$ & $1.91(0.47)$ & -1.491 & 0.150 & 0.61 & $1.41(0.30)$ & $1.91(0.46)$ & -3.175 & $0.004^{*}$ & 1.29 \\
\hline Peak eccentric power $[\mathrm{W} / \mathrm{kg}]$ & $20.42(3.72)$ & $21.34(3.96)$ & -0.582 & 0.566 & 0.24 & $16.19(3.38)$ & $17.05(3.5)$ & -0.613 & 0.546 & 0.25 \\
\hline Eccentric work $[\mathrm{J} / \mathrm{kg}]$ & $1.08(0.16)$ & $1.08(0.18)$ & -0.007 & 0.994 & 0.003 & $0.96(0.19)$ & $0.96(0.16)$ & -0.099 & 0.922 & 0 \\
\hline \multicolumn{11}{|l|}{ Total } \\
\hline Eccentric work $[\mathrm{J} / \mathrm{kg}]$ & $3.16(0.49)$ & $3.11(0.34)$ & 0.315 & 0.756 & 0.12 & $3.48(0.27)$ & $3.09(0.22)$ & 3.952 & $0.001 *$ & 1.58 \\
\hline
\end{tabular}

ES: effect size.

Table 5

Means (SD), $t$ values, $P$ values, and ES values associated with independent $t$ tests for average EMG (aEMG) values

\begin{tabular}{|c|c|c|c|c|c|c|c|c|c|c|}
\hline & \multicolumn{5}{|c|}{ Landing } & \multicolumn{5}{|c|}{ Drop jump } \\
\hline & Swimmer & Jumper & $t$ & $P$ & $\mathrm{ES}$ & Swimmer & Jumper & $t$ & $P$ & ES \\
\hline \multicolumn{11}{|l|}{$\mathrm{BF}$} \\
\hline aEMG-0 & $0.20(0.10)$ & $0.14(0.11)$ & 1.392 & 0.178 & 0.571 & $0.19(0.10)$ & $0.14(0.08)$ & 1.298 & 0.208 & 0.552 \\
\hline aEMG-1 & $0.57(0.31)$ & $0.41(0.19)$ & 1.498 & 0.148 & 0.622 & $0.58(0.25)$ & $0.48(0.27)$ & 0.962 & 0.347 & 0.384 \\
\hline \multicolumn{11}{|l|}{ VM } \\
\hline aEMG-0 & $0.07(0.03)$ & $0.10(0.08)$ & -1.529 & 0.148 & 0.497 & $0.06(0.03)$ & $0.07(0.05)$ & -0.845 & 0.410 & 0.243 \\
\hline aEMG-1 & $0.87(0.96)$ & $0.56(0.30)$ & 1.067 & 0.298 & 0.436 & $0.74(0.58)$ & $0.62(0.25)$ & 0.683 & 0.502 & 0.269 \\
\hline \multicolumn{11}{|l|}{ GM } \\
\hline aEMG-0 & $0.48(0.16)$ & $0.38(0.27)$ & 1.135 & 0.268 & 0.451 & $0.45(0.21)$ & $0.33(0.24)$ & 1.306 & 0.205 & 0.532 \\
\hline aEMG-1 & $0.27(0.19)$ & $0.37(0.22)$ & -1.083 & 0.290 & 0.487 & $0.25(0.13)$ & $0.33(0.17)$ & -1.248 & 0.225 & 0.529 \\
\hline \multicolumn{11}{|l|}{$\mathrm{BF} / \mathrm{VM}$} \\
\hline aEMG-0 & $3.41(1.86)$ & $3.59(6.61)$ & -0.092 & 0.928 & 0.037 & 3.74 (1.95) & $4.41(7.30)$ & -0.305 & 0.763 & 0.125 \\
\hline aEMG-1 & $0.99(0.77)$ & $0.90(0.51)$ & 0.328 & 0.746 & 0.138 & $1.0(0.60)$ & $0.90(0.55)$ & 0.417 & 0.681 & 0.174 \\
\hline
\end{tabular}

ES: effect size.

pared for the drop landing between the jumpers and swimmers (Table 4). No significant differences were observed for any lower extremity kinetic variables (i.e., joint moment, work, and power).

For the drop jumping, significant differences were observed for the hip, knee, and ankle kinetic variables (Table 4). The peak knee extension moment $(P=$ $0.039)$ and ankle plantarflexion moment $(P=0.004)$ were significantly greater in the jumpers than the swimmers. No significant differences were observed for the peak eccentric power in the hip, knee, and ankle joints. During the drop jumping, significantly smaller total lower extremity eccentric work was observed in the jumpers compared to the swimmers $(P=0.001)$. For each specific joint, the knee eccentric work was significantly lower in the jumpers compared to the swimmers $(P=0.001)$, resulting in a significantly smaller contribution of the jumpers' knees to the total eccen- tric work (Fig. 1). Finally, the anterior tibia shear force (ATSF) was significantly greater in the jumpers than the swimmers $(P<0.001)$.

\section{5. $E M G$}

The mean values for the aEMG of each selected muscle were compared for the drop landing and drop jumping between the jumpers and the swimmers (Table 5). No significant differences between the jumpers and the swimmers were observed for the aEMG in any selected lower extremity muscles.

\section{Discussion}

The role of plyometric training in preventing noncontact ACL injuries in the long term is still uncertain. 
Despite female jumpers having greater knee strength, which supported our hypothesis, they did not exhibit reduced risks of injury in their kinematics or kinetics, or muscular activity during both drop landing and drop jumping compared with female swimmers. The results suggest that female jumpers did not present any training-induced modification in landing mechanics or superior neuromuscular control during landing tasks than the swimmers did, which rejects our hypothesis regarding landing biomechanics.

Liederbach et al. [40] found that dancers suffer much lower incidence of ACL injuries (0.009 ACL injuries per 1000 exposures) compared with team sports $(0.07$ to $0.31 \mathrm{ACL}$ injuries per 1000 exposures). Furthermore, no differences in landing biomechanics between male and female professional dancers were found [41]. Authors believe that rigorous jump-specific and balancespecific training from a very young age may counteract risk factors in landing biomechanics observed in female athletes following maturity [41]. In contrast to professional dancers, college athletes from sports that involve extensive jumping movements (jumpers) did not start jump-specific and balance-specific training from an early age. This study revealed that plyometric training alone started from teenage years for female athletes may not diminish negative adaptations in landing biomechanics associated with ACL injury risks following maturity. Interestingly, our previous study found that male jumpers had greater hamstring strength and a landing technique with less ACL injury risk compared with male non-jumpers. The absence of similar adaptations in female athletes may explain gender disparity in ACL injuries [42].

For the drop jumping, several risk factors of ACL injury were even greater in the jumpers compared to the swimmers. Increased GRF during landing was found to associate with a higher risk of ACL injury [43,44]. In our study, the jumpers exhibited similar peak VGRF compared to the swimmers during the drop landing and exhibited much higher VGRF during the drop jumping. As another risk variable, the ATSF has been reported to increase the strains in the anteromedial bundle of the ACL in many previous in vivo and in vitro studies [4547]. Significantly greater ATSF was observed in the jumpers compared to the swimmers during the drop jumping. Co-contraction of the hamstring is supposed to lower the ATSF as it could provide a posterior force on the proximal tibia [47]. However, many studies have found that the counteractive effect of the hamstring is not significant during the start of knee flexions [48-50]. Because the peak ATSF during landing normally occurs soon after ground contact, it remains a question whether the greater concentric strength of the jumpers could help them lower the ASTF during landing tasks. Therefore, although the plyometric training significantly improved their lower extremity strength, it may not decrease the risk of non-contact ACL injury to female athletes during drop jumping.

Landing with more knee flexion is an important training-induced modification that may reduce the risk of ACL injury by decreasing ACL loads that occur after landing [37]. It is assumed that athletes with experience undertaking landing exercises will exhibit reduced risk in their landing mechanics than less experienced athletes [51]. Studies have shown that isolated plyometric training in the short term could produce this modification [22,52]. However, the results of female jumpers in the current study did not show a similar trend. For both of the two landing tasks, the female jumpers still landed with an extended knee angle, which decreases the ability of the hamstring muscles to prevent anterior tibial translation, thereby increasing the risk of ACL injury [53]. In agreement with our results, Collings et al. [51] found that female netball players did not exhibit different landing mechanics to female athletes with minimal experience playing sports requiring frequent landings. However, one limitation in their study is that the inexperienced group consisted of female athletes with less than one season of experience playing jumplanding sports, rather than consisting of well-trained female athletes who had never played a jumping/landing sport such as swimmers. It is also noteworthy that the female jumpers recruited in the current study were undertaking daily regular plyometric training. Therefore, the results of the current study could reveal that plyometric training as a single component may not guarantee the development of low risk landing mechanics for female athletes.

The inability of female athletes to improve knee flexion during landing in response to plyometric training may be due to several factors. One possible reason is that jumpers had not received enough effective feedback or instructions with regards improving landing mechanics during their plyometric training [51]. In ACL injury prevention or plyometric training, common instructions are "land with a flexed knee", or "land with your feet shoulder-width apart" [54]. This feedback or instruction directs the athlete's attention to their movements. In the motor learning domain, this kind of attentional focus is termed internal focus (IF) [55]. Improvements in movement patterns using IF instructions are generally not sustained over time $[16,56]$. In- 
stead, an external focus of attention may facilitate motor learning more effectively due to the utilization of automatic motor control. Another possible explanation could be the lower strength and training efficiency in female athletes compared to male athletes. It is noteworthy that male athletes could have developed low risk landing mechanics during their regular plyometric training [52]. Male non-jumpers from our previous study [52] showed much greater normalized quadriceps eccentric strength than female non-jumpers in the current study $\left(\mathrm{Q}_{e c c}: 2.52 \mathrm{vs} 1.99 \mathrm{Nm} / \mathrm{Kg}\right)$, and the difference between male jumpers and female jumpers was even bigger ( $\mathrm{Q}_{e c c}: 3.4$ vs $\left.2.66 \mathrm{M} . \mathrm{N} / \mathrm{kg}\right)$. Although the exact relationship between normalized quadriceps eccentric strength and knee flexion angle during landing has not been established, it may be necessary for female athletes to have improved normalized quadriceps eccentric strength comparable to male athletes in order to employ a more flexed knee joint prior to contact [9].

Bobbert et al. [57] observed two jumping techniques exhibited by participants in the performance of a drop jump. The first one was a bounce drop jump (BDJ), requiring a small amplitude and shorter time duration of downward movement. The second technique was a countermovement drop jump (CDJ), which involves a large downward movement after landing from the drop. Female swimmers in the current study exhibited significantly greater peak flexion angles and downward joint ROM, and increased stance time, i.e. a soft landing and countermovement drop jump. Landing softly and landing with greater knee flexion may reduce ACL loading during landing [58]. However, from the point of view of performance, increasing the range of eccentric contractions would reduce performance due to the possible effect of reduced short-range stiffness [59]. Short-range stiffness refers to muscles performing like a spring when the length change of the muscle during a stretch is very short. Also, the actin-myosin interaction in cross bridges could be detached when the muscle is overstretched $[60,61]$. It was suggested that BDJ is better than CDJ for improving the mechanical output of knee extensors and plantar flexors [57]. Given that most ACL tears occurred during the 50-100 ms after initial contact, landing with greater knee flexion at IC and reversing the downward movement [57] as soon as possible may be effective in achieving greater performance as well as reducing ACL risks. Additionally, utilizing an external focus of attention during plyometric training may be a promising way to improve performance as well as reduce injury risks [62]. Future research should focus on optimizing the implementation of EF instruc- tion in plyometric training to decrease the risk of an ACL injury [63].

There are several limitations in the study and caution is needed when generalizing the findings. Our study was a cross-sectional, so the group differences may not be entirely attributable to plyometric training alone. Other training variables, such as intensity, volume, frequency, and individual strength may not be the same for jumpers and swimmers. Certainly, a longitudinal study design would provide even more valid data. Second, landing maneuvers performed on the playing field during practice and competition may yield different biomechanical patterns compared with drop landing. Finally, we did not measure hip and ankle strength, which may add additional insight into the gender disparity in ACL injuries.

In summary, the current study revealed that that female jumpers did not present any training-induced modification in landing mechanics regarding reducing injury risks than the swimmers did. It suggested that plyometric training as a single component started from teenage years for female athletes may not guarantee the development of low risk landing mechanics. An efficient and easily adhered injury-prevention program should require athletes to perform landings with greater knee flexion at IC and reverse the downward movement quickly, which could improve performance as well as reduce injury risks.

\section{Acknowledgments}

The authors have no acknowledgments.

\section{Author contributions}

PERFORMANCE OF WORK: Xin Zhang and Jing Hu. INTERPRETATION OR ANALYSIS OF DATA: Xie Wu.

PREPARATION OF THE MANUSCRIPT: Mianfang Ruan and Qiang Zhang. REVISION FOR IMPORTANT INTELLECTUAL CONTENT: Mianfang Ruan and Qiang Zhang. SUPERVISION: Xie Wu.

\section{Ethical considerations}

The study has been approved by the Ethics Committee of Scientific Study at Shanghai University of Sport (No. 102772021RT042) on Jan. 19th, 2021 and all participants have signed an informed consent form. 


\section{Conflict of interest}

No potential conflict of interest was reported by the authors.

\section{Funding}

This study is supported by the National Natural Science Foundation of China (Grant No. 31871204).

\section{References}

[1] McNitt-Gray JL. Kinetics of the lower extremities during drop landings from three heights. J Biomech. 1993; 26(9): 1037-46.

[2] Plessa EI, Rousanoglou EN, Boudolos KD. Comparison of the take-off ground reaction force patterns of the pole vault and the long jump. J Sports Med Phys Fitness. 2010; 50(4): 416-21.

[3] Nagano Y, Ida H, Akai M, Fukubayashi T. Gender difference in knee kinematics and muscle activity during single limb drop landing. Knee. 2007; 14(3): 218-23.

[4] Gray J, Taunton JE, McKenzie DC, Clement DB, McConkey JP, Davidson RG. A survey of injuries to the anterior cruciate ligament of the knee in female basketball players. Int J Sports Med. 1985; 6(6): 314-6

[5] Agel J, Arendt EA, Bershadsky B. Anterior cruciate ligament injury in national collegiate athletic association basketball and soccer: a 13-year review. Am J Sports Med. 2005; 33(4): 524 30 .

[6] Kernozek TW, Torry MR, Iwasaki M. Gender differences in lower extremity landing mechanics caused by neuromuscular fatigue. Am J Sports Med. 2008; 36(3): 554-65.

[7] Voskanian N. ACL Injury prevention in female athletes: review of the literature and practical considerations in implementing an ACL prevention program. Curr Rev Musculoskelet Med. 2013; 6(2): 158-63.

[8] Hewett TE, Myer GD, Ford KR, Heidt RS, Colosimo AJ, McLean SG, et al. Biomechanical measures of neuromuscular control and valgus loading of the knee predict anterior cruciate ligament injury risk in female athletes: A prospective study. The American Journal of Sports Medicine. 2005; 33(4): 492 501.

[9] Lephart SM, Ferris CM, Riemann BL, Myers JB, Fu FH. Gender differences in strength and lower extremity kinematics during landing. Clin Orthop Relat Res. 2002(401): 162-9.

[10] Sugimoto D, Myer GD, Foss KD, Hewett TE. Specific exercise effects of preventive neuromuscular training intervention on anterior cruciate ligament injury risk reduction in young females: meta-analysis and subgroup analysis. Br J Sports Med. 2015; 49(5): 282-9.

[11] Hewett TE, Ford KR, Myer GD. Anterior cruciate ligamen injuries in female athletes: Part 2, a meta-analysis of neuromuscular interventions aimed at injury prevention. Am J Sports Med. 2006; 34(3): 490-8.

[12] Alentorn-Geli E, Myer GD, Silvers HJ, Samitier G, Romero D, Lazaro-Haro C, et al. Prevention of non-contact anterior cruciate ligament injuries in soccer players. Part 1: Mechanisms of injury and underlying risk factors. Knee Surg Sports Traumatol Arthrosc. 2009; 17(7): 705-29.

[13] Agel J, Arendt EA, Bershadsky B. Anterior cruciate ligament injury in national collegiate athletic association basketball and soccer: a 13-year review. The American Journal of Sports Medicine. 2005; 33(4): 524-30.

[14] Sugimoto D, Myer GD, McKeon JM, Hewett TE. Evaluation of the effectiveness of neuromuscular training to reduce anterior cruciate ligament injury in female athletes: a critical review of relative risk reduction and numbers-needed-to-treat analyses. Br J Sports Med. 2012; 46(14): 979-88.

[15] Herrington LC, Comfort P. Training for prevention of ACL injury: Incorporation of progressive landing skill challenges into a program. Strength and Conditioning Jounal. 2013; 35(6): 59-65.

[16] Gokeler A, Benjaminse A, Seil R, Kerkhoffs G, Verhagen E. Using principles of motor learning to enhance ACL injury prevention programs. Sports Orthop Traumatol. 2018; 34(1): 23-30.

[17] Hewett TE, Stroupe AL, Nance TA, Noyes FR. Plyometric training in female athletes. Decreased impact forces and in creased hamstring torques. Am J Sports Med. 1996; 24(6): 765-73.

[18] Bobbert MF, Huijing PA, van Ingen Schenau GJ. Drop jumping. II. The influence of dropping height on the biomechanics of drop jumping. Med Sci Sports Exerc. 1987; 19(4): 339-46.

[19] Toumi H, Best TM, Martin A, F'Guyer S, Poumarat G. Effects of eccentric phase velocity of plyometric training on the vertical jump. Int J Sports Med. 2004; 25(5): 391-8.

[20] Salonikidis K, Zafeiridis A. The effects of plyometric, tennisdrills, and combined training on reaction, lateral and linear speed, power, and strength in novice tennis players. J Strength Cond Res. 2008; 22(1): 182-91.

[21] Asadi A, Arazi H, Young WB, Saez de Villarreal E. The effects of plyometric training on change-of-direction ability: A metaanalysis. Int J Sports Physiol Perform. 2016; 11(5): 563-73.

[22] Myer GD, Ford KR, McLean SG, Hewett TE. The effects of plyometric versus dynamic stabilization and balance training on lower extremity biomechanics. Am J Sports Med. 2006; 34(3): 445-55.

[23] Yoo JH, Lim BO, Ha M, Lee SW, Oh SJ, Lee YS, et al. A meta-analysis of the effect of neuromuscular training on the prevention of the anterior cruciate ligament injury in female athletes. Knee Surg Sports Traumatol Arthrosc. 2010; 18(6): 824-30.

[24] Pfile KR, Hart JM, Herman DC, Hertel J, Kerrigan DC, In gersoll CD. Different exercise training interventions and droplanding biomechanics in high school female athletes. J Athl Train. 2013; 48(4): 450-62.

[25] Willadsen EM, Zahn AB, Durall CJ. What is the most effective training approach for preventing noncontact ACL injuries in high school-aged female athletes? J Sport Rehabil. 2018; 1-5.

[26] Brown TN, Palmieri-Smith RM, McLean SG. Comparative adaptations of lower limb biomechanics during unilateral and bilateral landings after different neuromuscular-based ACL injury prevention protocols. J Strength Cond Res. 2014; 28(10): 2859-71.

[27] Baldon Rde M, Moreira Lobato DF, Yoshimatsu AP, dos Santos AF, Francisco AL, Pereira Santiago PR, et al. Effect of plyometric training on lower limb biomechanics in females. Clin J Sport Med. 2014; 24(1): 44-50.

[28] Alikhani R, Shahrjerdi S, Golpaigany M, Kazemi M. The effect of a six-week plyometric training on dynamic balance and knee proprioception in female badminton players. J Can Chiropr Assoc. 2019; 63(3): 144-53.

[29] Ghena DR, Kurth AL, Thomas M, Mayhew J. Torque Characteristics of the Quadriceps and Hamstring Muscles during Concentric and Eccentric Loading. J Orthop Sports Phys Ther. 
1991; 14(4): 149-54.

[30] Griffin JW, Tooms RE, vander Zwaag R, Bertorini TE, O’Toole ML. Eccentric muscle performance of elbow and knee muscle groups in untrained men and women. Med Sci Sports Exerc. 1993; 25(8): 936-44.

[31] Aagaard P, Simonsen EB, Beyer N, Larsson B, Magnusson P, Kjaer M. Isokinetic muscle strength and capacity for muscular knee joint stabilization in elite sailors. Int J Sports Med. 1997; 18(7): 521-5.

[32] Zhang Q, Ruan M, Singh NB, Huang L, Zhang X, Wu X. Progression of fatigue modifies primary contributors to ground reaction forces during drop landing. J Hum Kinet. 2021; 76: 161-73.

[33] Guy-Cherry D, Alanazi A, Miller L, Staloch D, OrtizRodriguez A. Landing Styles Influences Reactive Strength Index without Increasing Risk for Injury. Sports Med Int Open. 2018; 2(2): E35-E40.

[34] Pappas E, Hagins M, Sheikhzadeh A, Nordin M, Rose D. Peak biomechanical variables during bilateral drop landings: comparisons between sex (female/male) and fatigue (prefatigue/post-fatigue). N Am J Sports Phys Ther. 2009; 4(2): 83-91.

[35] Winter D. Biomechanics and motor control of human movement. New York: John Wiley and Sons, 1990.

[36] Ruan M, Zhang Q, Wu X. Acute effects of static stretching of hamstring on performance and anterior cruciate ligament injury risk during stop-jump and cutting tasks in female athletes. J Strength Cond Res. 2017; 31(5): 1241-50.

[37] Yu B, Lin CF, Garrett WE. Lower extremity biomechanics during the landing of a stop-jump task. Clin Biomech (Bristol, Avon). 2006; 21(3): 297-305.

[38] Hewett TE, Myer GD, Zazulak BT. Hamstrings to quadriceps peak torque ratios diverge between sexes with increasing isokinetic angular velocity. J Sci Med Sport. 2008; 11(5): 452-9.

[39] Cohen J. Statistical Power Analysis for the Behavioral Sciences. 2nd ed. Hillsdale, NJ: Lawrence Erlbaum Associates, 1988.

[40] Liederbach M, Dilgen FE, Rose DJ. Incidence of anterior cruciate ligament injuries among elite ballet and modern dancers - A 5-year prospective study. American Journal of Sports Medicine. 2008; 36(9): 1779-88.

[41] Orishimo KF, Kremenic IJ, Pappas E, Hagins M, Liederbach M. Comparison of Landing Biomechanics Between Male and Female Professional Dancers. American Journal of Sports Medicine. 2009; 37(11): 2187-93.

[42] Quatman CE, Ford KR, Myer GD, Hewett TE. Maturation leads to gender differences in landing force and vertical jump performance - A longitudinal study. American Journal of Sports Medicine. 2006; 34(5): 806-13.

[43] Leppanen M, Pasanen K, Kujala UM, Vasankari T, Kannus P, Ayramo S, et al. Stiff landings are associated with increased acl injury risk in young female basketball and floorball players. Am J Sports Med. 2017; 45(2): 386-93.

[44] Lin CF, Liu H, Gros MT, Weinhold P, Garrett WE, Yu B. Biomechanical risk factors of non-contact ACL injuries: A stochastic biomechanical modeling study. Journal of Sport and Health Science. 2012; 1(1): 36-42.

[45] Markolf KL, Burchfield DI, Shapiro MM, Shepard ME, Finerman GAM, Slauterbeck JL. Combined knee loading states that generate high anterior cruciate ligament forces. Journal of Orthopaedic Research. 1995; 13(6): 930-5.

[46] Fleming BC, Renstrom PA, Beynnon BD, Engstrom B, Peura GD, Badger GJ, et al. The effect of weightbearing and ex- ternal loading on anterior cruciate ligament strain. Journal of Biomechanics. 2001; 34(2): 163-70.

[47] Yu B, Garrett WE. Mechanisms of non-contact ACL injuries. Br J Sports Med. 2007; 41(Suppl 1): i47-51.

[48] Kingma I, Aalbersberg S, van Dieen JH. Are hamstrings activated to counteract shear forces during isometric knee extension efforts in healthy subjects? Journal of Electromyography and Kinesiology. 2004; 14(3): 307-15.

[49] Li G, Rudy TW, Sakane M, Kanamori A, Ma CB, Woo SLY The importance of quadriceps and hamstring muscle loading on knee kinematics land in-situ forces in the ACL. Journal of Biomechanics. 1999; 32(4): 395-400.

[50] Pandy MG, Shelburne KB. Dependence of cruciate-ligament loading on muscle forces and external load. Journal of Biomechanics. 1997; 30(10): 1015-24.

[51] Collings TJ, Gorman AD, Stuelcken MC, Mellifont DB, Sayers MGL. Do the landing mechanics of experienced netball players differ from those of trained athletes competing in sports that do not require frequent landings? J Sci Med Sport. 2020; 23(1): 48-52.

[52] Wu X, Zhang S, Liu Y, Zhang D, Xie B. Do knee concentric and eccentric strength and sagittal-plane knee joint biomechanics differ between jumpers and non-jumpers in landing? Hum Mov Sci. 2013; 32(6): 1299-309.

[53] Ray Fagenbaum WGD. Jump landing strategies in male and female college athletes and the implications of such strategies for anterior cruciate ligament injury. Am J Sports Med. 2003; 31(2): 233-40.

[54] Myklebust G, Engebretsen L, Braekken IH, Skjolberg A, Olsen $\mathrm{OE}, \mathrm{Bahr}$ R. Prevention of anterior cruciate ligament injuries in female team handball players: a prospective intervention study over three seasons. Clin J Sport Med. 2003; 13(2): 71-8.

[55] Wulf G, Hoss M, Prinz W. Instructions for motor learning: differential effects of internal versus external focus of attention. J Mot Behav. 1998; 30(2): 169-79.

[56] DiStefano LJ, Marshall SW, Padua DA, Peck KY, Beutler AI, de la Motte SJ, et al. The Effects of an Injury Prevention Program on Landing Biomechanics Over Time. Am J Sports Med. 2016; 44(3): 767-76.

[57] Bobbert MF, Huijing PA, Ingen Schenau GJV. Drop jumping. I. The influence of jumping technique on the biomechanics of jumping. Medicine and Science in Sports and Exercise. 1987a; 19: 332-8.

[58] Dai B, Garrett WE, Gross MT, Padua DA, Queen RM, Yu B. The effects of 2 landing techniques on knee kinematics, kinetics, and performance during stop-jump and side-cutting tasks. Am J Sports Med. 2015; 43(2): 466-74.

[59] Bosco C, Komi PV. Potentiation of the mechanical behavior of human skeletal muscle through prestretching. Acta Physiologica Scandinavica. 1979; 106: 467-72.

[60] Flitney FW, Hirst DG. Cross-bridge detachment and sarcomere 'give' during stretch of active frog's muscle. J Physiol. 1978; 276: 449-65.

[61] Syme DA, Grattan MJ. Effects of stretch on work from fast and slow muscles of mice: damped and undamped energy release. Can J Physiol Pharmacol. 2002; 80(9): 887-900.

[62] Makaruk H, Porter JM, Czaplicki A, Sadowski J, Sacewicz T. The role of attentional focus in plyometric training. J Sports Med Phys Fitness. 2012; 52(3): 319-27.

[63] Benjaminse A, Welling W, Otten B, Gokeler A. Novel methods of instruction in ACL injury prevention programs, a systematic review. Phys Ther Sport. 2015; 16(2): 176-86. 